\title{
Experimental study on the model of the correlation between the movement of the drilling string with big diameter of drill and effects on the oil rigs
}

\author{
Marius Stan • Lazar Avram
}

Received: 17 December 2013/Accepted: 21 July 2014/Published online: 24 August 2014

(C) The Author(s) 2014. This article is published with open access at Springerlink.com

\begin{abstract}
Drilling rigs are equipped with a modern hoisting system, for movement of the long string, by means of topdrive with all functions involved which is used to carry out special up and down functions. A great importance in the dynamic study of a working system operation is given to the way in which the system structure is set. A first concern in this regard was to set the structure of the working system and exploitations for displacements and vibrations as a continuous system. It is considered a drill pipe with realistic features. The article discovers some issues, develop mathematical model for the study of dynamic drilling string and study on the effects on the structure of mechanical wave propagation in drilling string. It interacts with structural friction, viscous and dry, between borehole and drill pipe in the paper we find the models of interaction for everyone in part. The Hoisting system model developed in the laboratory is reduced by the similarity of the installation for drilling large-diameter wells. Theoretical results are obtained by numerical simulation modeling. The validation is done indirectly by tracing the evolution pressures graphics as a result of displacement of the lower end of the drilling string model. During experimental research has found that it has important effect moving the upper (topdrive) and the mechanical stresses and displacements of the structure of the model.
\end{abstract}

Keywords Model $\cdot$ Hoisting system · Drilling rig · Simulation

\footnotetext{
M. Stan $(\bowtie) \cdot$ L. Avram

University of Petroleum-Gas Ploiesti, Bd. Bucureşti 39, Ploiesti, Romania

e-mail: mstan@upg-ploiesti.ro

L. Avram

e-mail: lavram@upg-ploiesti.ro
}

\section{Introduction}

Modern drilling rigs are equipped with a hoisting system of engagement at the top.

The article has two parts. The first part consists in establishing the theoretical model and solved by numerical simulation. The second part refers to experimental research.

The topdrive system is having the function to carry out special functions such as rotating the drill string during the lifting operation up and down.

\section{Methods for modeling the dynamics of the drilling string}

It has also been considered that energy loss of the drilling string results through displacement with viscous and dry amortization. Moreover, a new element has been that structural amortization (complex factor for amortization) is important. The load is from the system inertia, overcoming gel resistance and hydrodynamic pressure due to plunger effect at drill bit (Avram 1995; Avram and Stan 2010; Avram and Troquet 1999). Produced mechanical oscillations and displacements can become dangerous for both the drill string (area of threaded joints) and the surface structure on which the vibrations and shock have effect (Abrahamsen 2007).

Identifying these types of variations of the variables of force and speed, respectively, makes possible the study of the induced effects in the structure to movement of topdrive,(Abrahamsen and Reid 2007; Kim 2010; R.G. Shields (Canadian Marine Drilling Ltd.) 1994). The following scheme of calculation can be proposed, in which the following abbreviations can be noticed (Fig. 1): 


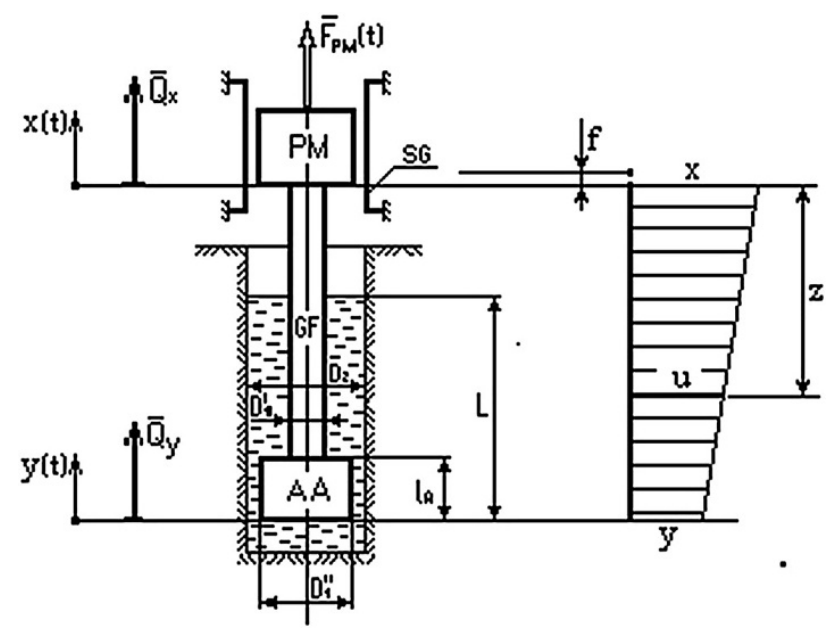

Fig. 1 The calculation scheme for establishing the mathematical model of the drilling string

$\mathrm{M}_{\mathrm{PM}}$-mass of elements on the mobile platform (topdrive);

$F$-active force, $F=F(t) ; x(t)$-movement of mobile platform (MP); MAA-concentrated mass at the bottom hole assembly level; GF-drilling string (drill pipe); $y(t)$ movement of bottom hole assembly; $f$-elastic deformation due to static loads.

Corresponding,

$m=m^{\prime}(1-\rho f / \rho o)$.

Lagrange equations for various energy forms:

$\frac{\mathrm{d}}{\mathrm{d} t}\left(\frac{\partial E}{\partial \dot{x}}\right)-\frac{\partial E}{\partial x}+\frac{\partial V}{\partial x}+\frac{\partial D}{\partial \dot{x}}=Q_{x}$

$\frac{\mathrm{d}}{\mathrm{d} t}\left(\frac{\partial E}{\partial \dot{y}}\right)-\frac{\partial E}{\partial y}+\frac{\partial V}{\partial y}+\frac{\partial D}{\partial \dot{y}}=Q_{y}$

$u=y+\frac{x-y+f}{L} \times(L-z)$.

Kinetic energy $E$ of the system made up of mobile platform, drill string and the bottom hole assembly:

$$
\begin{array}{r}
E=\frac{m_{\mathrm{EE}}}{2} \cdot\left(\frac{\partial u}{\partial t}\right)_{z=0}^{2}+\frac{\rho \cdot A}{2} \cdot \int_{0}^{l}\left(\frac{\partial u}{\partial t}\right)^{2} \mathrm{~d} z+\frac{m_{\mathrm{AA}}}{2} \cdot\left(\frac{\partial u}{\partial t}\right)_{z=L}^{2} \\
=\frac{m_{\mathrm{EE}} \cdot \dot{x}^{2}}{2}+\frac{m}{3} \cdot \frac{\dot{x}^{2}+\dot{x} \cdot \dot{y}+\dot{y}^{2}}{2}+\frac{m_{\mathrm{AA}} \cdot \dot{y}^{2}}{2}
\end{array}
$$

$V$-potential energy in the system platform, drill string bottom hole assembly.

$$
\begin{aligned}
& V=V_{1}+V_{2}+m_{\mathrm{AA}} \cdot g \cdot y+m_{\mathrm{EE}} \cdot g \cdot x \\
& =G \cdot \frac{x+y+f}{2}+\frac{k}{2} \cdot(x-y+f)^{2}+G_{\mathrm{AA}} \cdot y+G_{\mathrm{EE}} \cdot x
\end{aligned}
$$

$V 1$-represents the variation of potential energy of the drill string as a result of movement:

$$
\begin{aligned}
& V_{1}=m \cdot g \cdot \int_{0}^{L} u(z) \mathrm{d} z=m \cdot g \cdot \int_{0}^{L}\left[y+\frac{x-y+f}{L} \cdot(L-z)\right] \mathrm{d} z \\
& =M \cdot g \cdot \frac{x+y+f}{2}
\end{aligned}
$$

$V 2$ - variation of the potential energy of the drill string as a result of elastic deformation:

$V_{2}=\frac{E A}{2} \cdot \int_{0}^{L}\left(\frac{\partial u}{\partial z}\right)^{2} \mathrm{~d} z=\frac{k}{2} \cdot(x-y+f)^{2}$

$k=\frac{E A}{L}$, elastic constant of the drill string (drill pipe)

$f$-elastic deformation due to static loads:

$f=\frac{1}{k} \cdot\left(m_{\mathrm{AA}} \cdot g+\frac{M \cdot g}{2}\right)$

$D$-dissipation function in the drilling string-well hole assembly system

It should be noted that to avoid non-linearity of expression in the Lagrange equation terms if there are internal forces of amortization, Lord Rayleigh defines a function that is canceled at zero speed and it is called the dissipation function $D$. Thus, the generalized amortization force, corresponding to a virtual change of generalized coordinates can be obtained as a derivative of the dissipation function in a section with generalized speed:

$Q_{x d}=\frac{\partial D}{\partial \dot{x}} ; Q_{y d}=\frac{\partial D}{\partial \dot{y}}$.

Dynamic analysis of a structure is carried out with specific notions of dynamics: mass, rigidity, amortization. Amortization plays an important role in determining the dynamic response of a stressed structure. Uncertainty may be of 20 ...30 \% in assessing and amortization changes the response at a rate of 15...40 \% (Avram 1995; Avram and Stan 2010)

\section{Viscous amortization}

Mechanical systems which oscillate in fluids, bodies that slide on lubricated areas, dissipate energy through viscous amortization. The dissipation function is: 
$D=\frac{k \cdot A}{2} \cdot \int_{0}^{L}\left[\frac{\partial}{\partial t}\left(\frac{\partial u}{\partial z}\right)\right]^{2} \mathrm{~d} z$

Replacing (4) in (11), the result is:

$D=\frac{k \cdot A}{2 L} \cdot(\dot{x}-\dot{y})^{2}=c \cdot \frac{(\dot{x}-\dot{y})^{2}}{2}$

and the derivate:

$\frac{\partial D}{\partial \dot{x}}=-\frac{\partial D}{\partial \dot{y}}=c \cdot(\dot{x}-\dot{y})$.

Structural amortization

Structural amortization may take place due to the phenomena that occur inside the materials forming structures, i.e., drill string (non-elasticity, flow phenomena, viscouselastic phenomena) and also due to contact between these elements which make up the assembly well-drill stringstructure guide movement. It can be concluded that the amortization force is proportional in intensity to the elastic force (return) and the opposite sense of speed, so it can be expressed as deriving from a potential:

$F_{d}=-i \cdot s \cdot \frac{\partial W}{\partial q}$

where:

$F_{d}$ represents the structural amortization force;

$q$ represents the generalized coordinates of the movement $q \in\{x, y\}$;

$\mathrm{s}$-constant; $i=\sqrt{-1}$

$D$ results in this case from the virtual mechanical work of the amortization forces:

$\delta D=\delta L=F_{d} \cdot \delta q=-i \cdot s \cdot \frac{\partial W}{\partial q} \cdot \delta q$.

The table shows some values of the loss coefficient $(\eta)$

The normal unitary effort, in case of materials that behave structurally, can be expressed by introducing a complex elasticity module:

$E^{\prime}=E \cdot(u+i \cdot v)$,

where,

$E$ represents the elasticity module for steel

Notations:

$u=\frac{1-\frac{\eta^{2}}{4}}{1+\frac{\eta^{2}}{4}}: \quad v=\frac{\eta}{1+\frac{\eta^{2}}{4}}$.

Variation of potential energy as a result of the produced deformation:

$V=\frac{E \prime \cdot A}{2} \cdot \int_{0}^{L}\left(\frac{\partial u}{\partial z}\right)^{2} \mathrm{~d} z=\frac{u+i \cdot v}{2} \cdot E A \int_{0}^{L}\left(\frac{\partial u}{\partial z}\right)^{2} \mathrm{~d} z$
Table 1 Loss coefficient $\eta$ for various materials (Avram 1995), (Subramanian and Azar 2000)

\begin{tabular}{ll}
\hline Material & Loss coefficient $\eta$ \\
\hline General use steel & $0.005 \ldots 0.010$ \\
Alloy steel & $0.001 \ldots 0.008$ \\
Cast iron & $0.020 \ldots 0.050$ \\
Aluminum alloys & 0.003 \\
\hline
\end{tabular}

For $\eta$ values corresponding to alloy steel (Table 1), it can be noticed $u \cong 1$. Relation (18) becomes:

$V=(1+i \cdot v) \cdot \frac{E A}{2} \cdot \int_{0}^{L}\left(\frac{\partial u}{\partial z}\right)^{2} \mathrm{~d} z=V_{2}+i \cdot v \cdot V_{2}$

Taking into account (19), the variation of total potential energy $V$, in the system mobile platform-drill stringbottom hole, (Mnatsakanov and Litvinov 1991; Le Nguyen 1993) assembly with structural amortization, becomes:

$$
\begin{array}{r}
V=G \cdot \frac{x+y+f}{2}+\left(1+i \cdot \frac{\eta}{1+\frac{\eta^{2}}{4}}\right) \cdot \frac{k}{2} \cdot(x-y+f)^{2} \\
+G_{A A} \cdot y+G_{E E} \cdot x
\end{array}
$$

Columbian amortization

Dry friction or Columbian amortization is a strong force that appears in the relative motion between the body and the surface, whose size is constant.

This depends only on the coefficient of sliding friction $(f)$ and normal reaction of the surface $(N)$ and the direction of this force is directed by the direction of the contact speed, but on the opposite sense, (Subramanian 2000):

Correspondingly,

$F=-f \cdot N \cdot \operatorname{sgn}\left(\frac{\partial x}{\partial t}\right)$.

It has also been considered that energy losses of the drill string result from viscous and dry amortization. Moreover, a new element has been discovered, that is structural amortization.

The load peak results from the system inertia, overcoming gel resistance and hydrodynamic pressure due to plunger effect.

Modeling the actions

To model the actions in the system (Avram 1995; Kim 2010; R.G. Shields (Canadian Marine Drilling Ltd.) 1994) the following calculation scheme is proposed (Fig. 2):

where: PM-mobile platform (topdrive); 
Table 2 Maximum depending on the $\alpha^{\circ}$ platform tilt angle

\begin{tabular}{|c|c|c|c|c|c|c|c|c|}
\hline \multirow{3}{*}{$\begin{array}{l}\text { Nr. } \\
\text { crt. }\end{array}$} & \multirow{3}{*}{$\begin{array}{l}\text { Nod } \\
i\end{array}$} & \multirow{3}{*}{$\begin{array}{l}\text { Nod } \\
j\end{array}$} & \multicolumn{6}{|c|}{$\sigma_{\mathrm{ech} \text { in } \mathrm{N} / \mathrm{mm}}^{2}$} \\
\hline & & & \multicolumn{2}{|l|}{$\alpha=3$} & \multicolumn{2}{|l|}{$\alpha=4$} & \multicolumn{2}{|l|}{$\alpha=5$} \\
\hline & & & $\operatorname{nod} i$ & $\operatorname{nod} j$ & $\operatorname{nod} i$ & $\operatorname{nod} j$ & $\operatorname{nod} i$ & $\operatorname{nod} j$ \\
\hline 1 & 17 & 165 & 13.01 & 54.28 & 23.04 & 8.9 & 35.86 & 13.33 \\
\hline 2 & 165 & 166 & 11.0 & 3.86 & 18.61 & 5,18 & 28.31 & 6.87 \\
\hline 3 & 166 & 167 & 15.43 & -0.02 & 27.81 & 0.04 & 43.62 & -0.09 \\
\hline 4 & 167 & 168 & 19.1 & 46,3 & 33.8 & 82.3 & 52.57 & 128 \\
\hline 5 & 168 & 50 & 34.6 & 20.8 & 63.7 & 38.8 & 101 & 61.9 \\
\hline 6 & 35 & 174 & -20.5 & 112 & -34.3 & 199 & -56.7 & 310 \\
\hline 7 & 174 & 175 & 21.59 & -4.7 & 38.61 & -8.6 & 60.34 & -13.6 \\
\hline 8 & 175 & 176 & 3.25 & 22.5 & 5.34 & 38.3 & 8.01 & 58.4 \\
\hline 9 & 176 & 177 & 20.80 & 46.69 & 35.36 & 83.7 & 54.6 & 131 \\
\hline 10 & 177 & 178 & -24.2 & 7.1 & -43.1 & 79.9 & -67.2 & 125 \\
\hline 11 & 169 & 170 & 3.44 & 17 & 6.19 & 30.2 & 9.65 & 47.1 \\
\hline 12 & 170 & 171 & -0.19 & 5.93 & 0.29 & 10.8 & 0.92 & 17.1 \\
\hline 13 & 171 & 172 & 23.68 & 29.14 & 42.6 & 52.0 & 66.8 & 81.4 \\
\hline 14 & 172 & 173 & 27.6 & 17.3 & 50.7 & 32.4 & 80.3 & 51.6 \\
\hline 15 & 179 & 175 & -7.32 & 13.53 & -12.7 & 23.8 & -19.5 & 36.9 \\
\hline 16 & 180 & 181 & 11.9 & -2.87 & 21.6 & -4.3 & 33.9 & -62.6 \\
\hline 17 & 181 & 182 & 6.15 & 37.1 & 10.7 & 66.9 & 16.5 & 105 \\
\hline
\end{tabular}

GF drill string (drill pipe)

AA bottom hole assembly

SG guiding structure of the platform

$\mathrm{D} 1^{\prime}$ external diameter of the drill string

D1" external diameter of the bottom hole

D2, well diameter.

Generalized functions are calculated using the following expressions:

$Q_{x}=F_{\mathrm{PM}}(t)+F_{f, \mathrm{PM}}$

where:

$\mathrm{F}_{\mathrm{PM}}(t)$ is the moving force that acts on the system mobile platform-bottom hole assembly;

$F_{f \text {,PM }}$ is the resultant of the friction forces corresponding to dry friction existence in the guiding elements of the mobile platform:

$F_{f, \mathrm{PM}}=-f \cdot N \cdot \operatorname{sgn}(\dot{u}) ;$

$Q_{y}=-G_{l}-F_{f, \mathrm{AA}}-F_{\mathrm{HS}}$

where:

$G l$ represents the weight of the mud engaged in movement when the bottom hole assembly is moved into the well:

$G_{l}=\rho_{f} \cdot g \cdot E \cdot \frac{\pi}{4} \cdot\left(D \prime_{1}^{2}-D_{1} \prime^{2}\right)$

$F_{f, \text { AA }}$ - the resultant of the friction forces, at the bottom home assembly level:
$F_{f, \mathrm{AF}}=k \cdot\left(G+G_{\mathrm{AF}}\right)$

$F_{\text {HS }}$-supplementary hydrodynamic force or supplementary force:

$F_{\mathrm{HS}}=F_{\mathrm{HS}_{1}}+F_{\mathrm{HS}_{2}}$

$F_{\mathrm{HS}_{1}}$ - component of the supplementary force resulted from overcoming the gel resistance when inducing the bottom hole assembly movement (Subramanian 2000).

$F_{\mathrm{HS}_{2}}$ - component of the supplementary force, due to supplementary pressure, that results from the swabbing of the bottom hole assembly in the well full of drilling mud (Martin 2003; Piroozianet al. 2012).

The equation system (2), (3), associated to the mathematical model becomes:

$\left\{\begin{array}{l}m_{1} \ddot{x}+\frac{M}{6} \ddot{y}+c(\dot{x}-\dot{y})+k(1+i s)(x-y+f) \\ =F_{\mathrm{PM}}(t)-f \cdot N \cdot \operatorname{sgn}(\dot{u})-F_{f, \mathrm{PM}}-\frac{G}{2}-G_{\mathrm{EE}} \\ \frac{M}{6} \cdot{ }^{\prime} x+m_{2} \cdot " y-c \cdot(\dot{x}-\dot{y})-k \cdot(1+i \cdot s) \\ \cdot(x-y+f) \\ =G_{l}-F_{f, \mathrm{AA}}-F_{\mathrm{HS}}-\frac{G}{2}-G_{\mathrm{AA}}\end{array}\right.$

where the following notations have been used:

$m_{1}=m_{\mathrm{EE}}+\frac{M}{3} \quad$ and $\quad m_{2}=m_{\mathrm{AA}}+\frac{M}{3}$. 


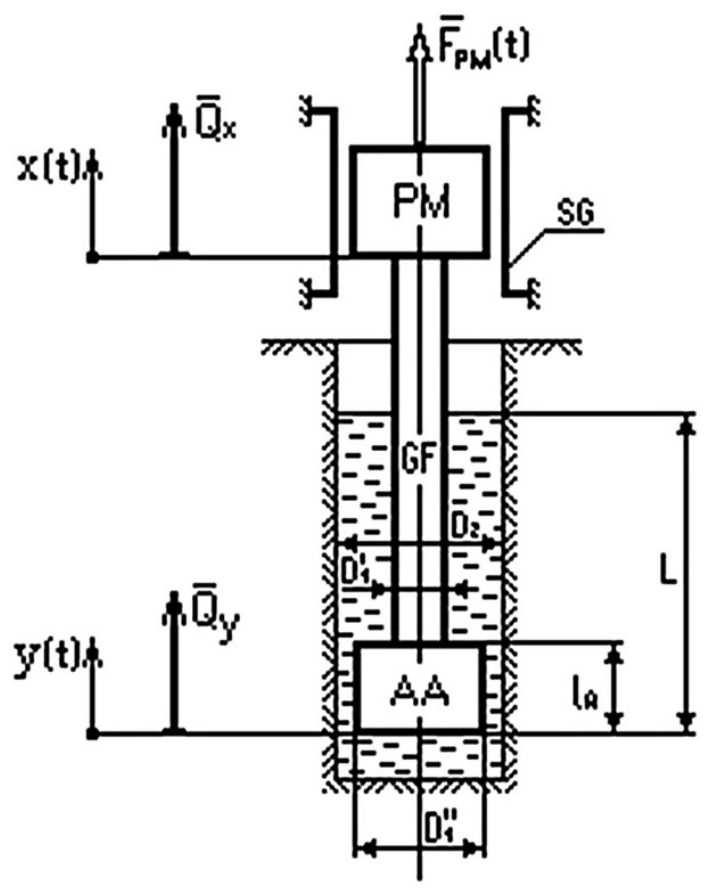

Fig. 2 Calculation scheme for modeling the actions

\section{Using computer simulation results}

Below are simulated graphic solutions of system equations using computers automatically? Noteworthy are the qualitative aspects of the curves obtained.

This will be an indirect way of validating the results because additional pressure to end will have the same evolution in time.

Graphs' results highlight the different modes in which the two ends of the drill string move at different speeds and accelerations.

a. Drilling head topdrive displacements [m]

b. Lower $y g(t)$ relative to starting position

c. Accelerations of the oscillating $\left[\mathrm{m} / \mathrm{s}^{2}\right]$

Simulation conditions for graphics above:

- 4,500 m depth for conventional drilling rig, not large diameter

- Drilling fluid density $1,260 \mathrm{~kg} / \mathrm{m}^{3}$

- Shear stress N/A

- $0.1143 \mathrm{~m}$ outside diameter of the rods

- $0.0925 \mathrm{~m}$ inner diameter rods

The facility (drilling test stand DTS)

DTS for the study of the behavior under complex dynamic system unconventional drilling is actually a copy by

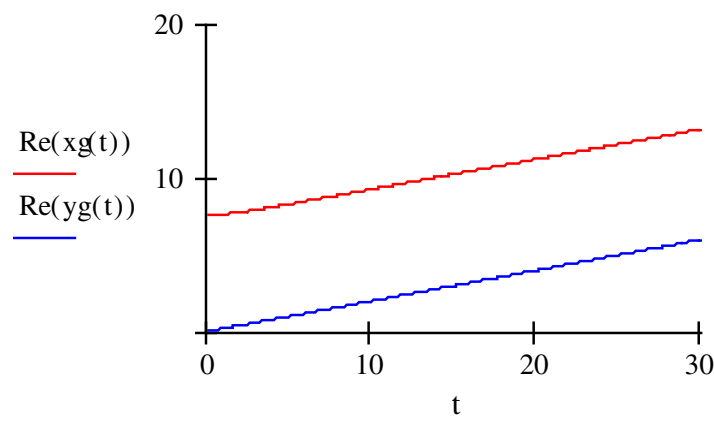

Fig. 3 Displacements up $x g$ and down $y g$

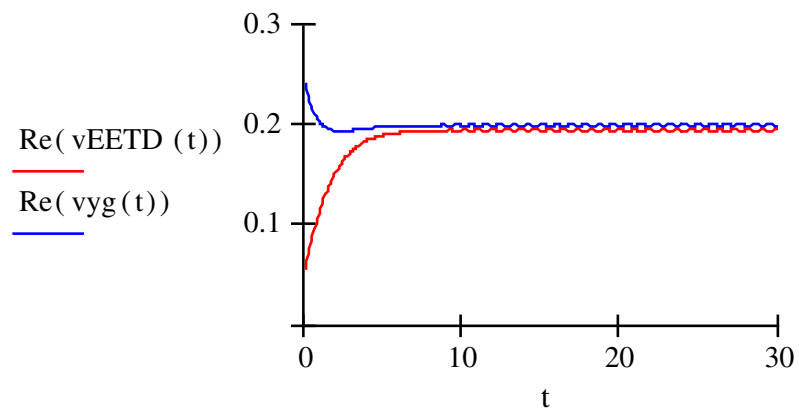

Fig. 4 Speeds up vEETD, down vyg

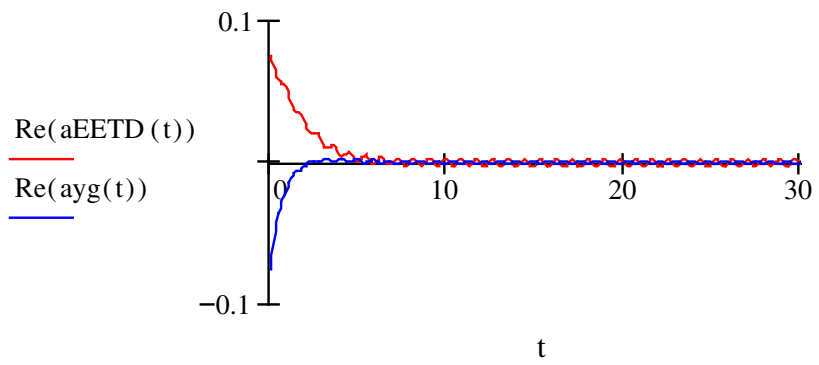

Fig. 5 Accelerations up aEETD, down ayg

reducing the size and scale of the masses the actual installation.

To obtain the model (Fig. 3) some similarity criteria were verified for achieving an acceptable degree of geometric similarity, kinematic and dynamic with real unconventional plant (Abrahamsen and Reid 2007; Stan 2010; http://zhengzhouhanfa.en.made-in-china.com).

Main Technical Parameter for KT5000 Type Fully Hydraulic Power Big Diameter Drilling Rig

Drilling Diameter (m) 5 Drilling Depth (m) 120

Rotation of Power Unit(r/min) 0-12

Max. Torque (kN. M) 400

Max. Lifting Capability (kN) 300 Diameter of Power Unit (mm) 350 


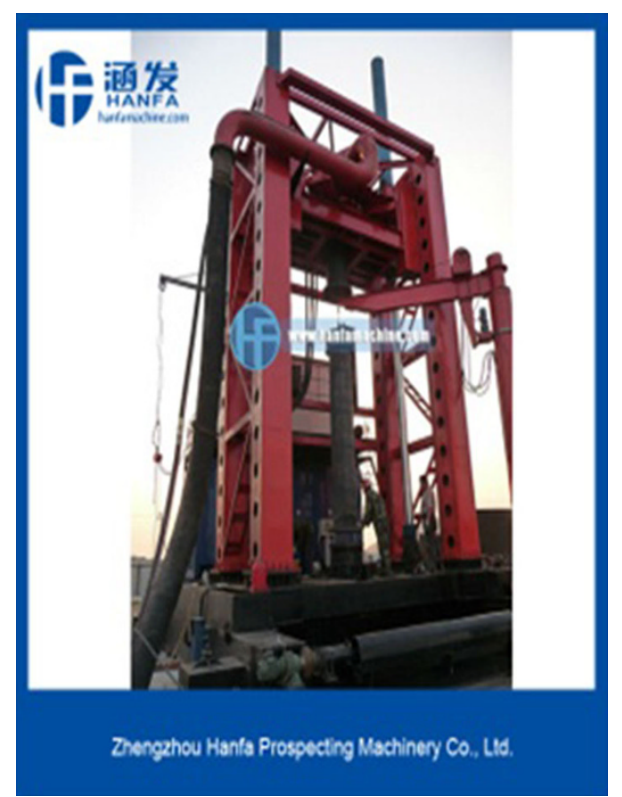

Fig. 6 Main Technical Parameter for KT5000 Type Fully Hydraulic Power Big Diameter Drilling Rig (http://zhengzhouhanfa.en.made-inchina.com)

Fig. 7 Presentation of the drilling test stand DTS obtained by similarity for research topdrive PDMS design (a principal schema, b DTS by UPG Ploiesti) (Subramanian and Azar 2000) $\mathbf{a}$

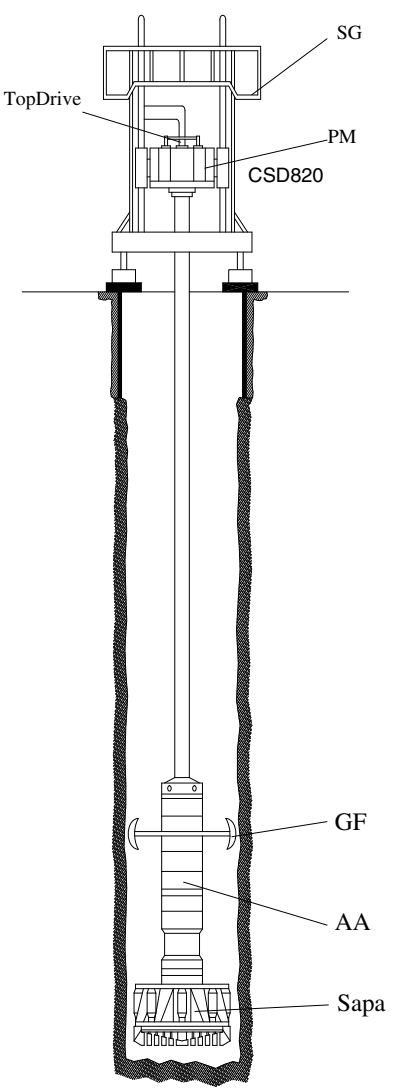

Course of Power Unit (m) 5 Pressure of Hydraulic System (MPa) 31.5

Slag Draining Mode Gaslift Counter Circulation Auxiliary Hoist $(t) 3$ Total Power (kw) 315 Overall Dimension (m) $12 \times 7.5 \times 10$ (Fig. 6 )

Stand trial for complex dynamic behavior of the system under unconventional maneuver is actually true copy by reducing the size and mass scale Romanian prototype installation FMP 900 presented in Fig. 7.

It is a construction-type spatial lattice obtained by welding the pipe and profile angle, as shown in the figure below.

Structure itself is equipped with vertical rollers running mobile platform during lifting and lowering of.

Reactive guiding structure is supported on a metallic structure that simulates real connection with the foundation of the real structure (Abrahamsen 2007).

The stand shows research facilities for mechanical stress analysis by electrical resistive tensometers.

To confirm the theoretical research of the mathematical model (Fig. 3), pressure variations are measured in a hydraulic cylinder mounted on the stand foundations

b

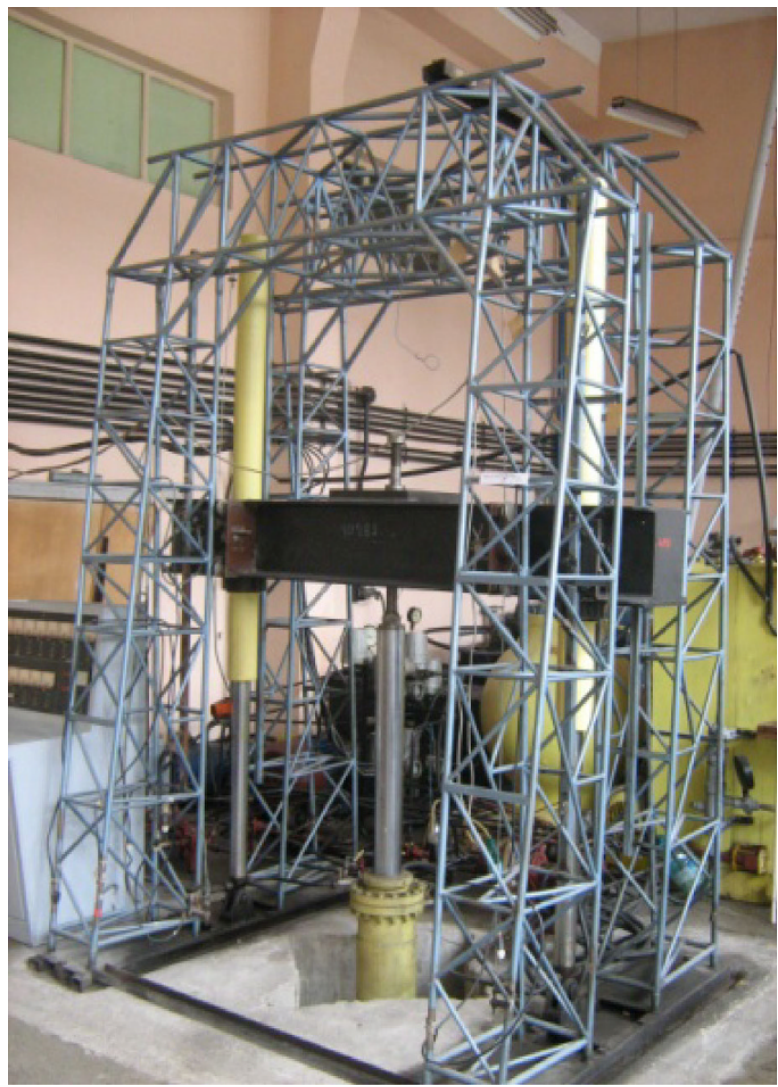




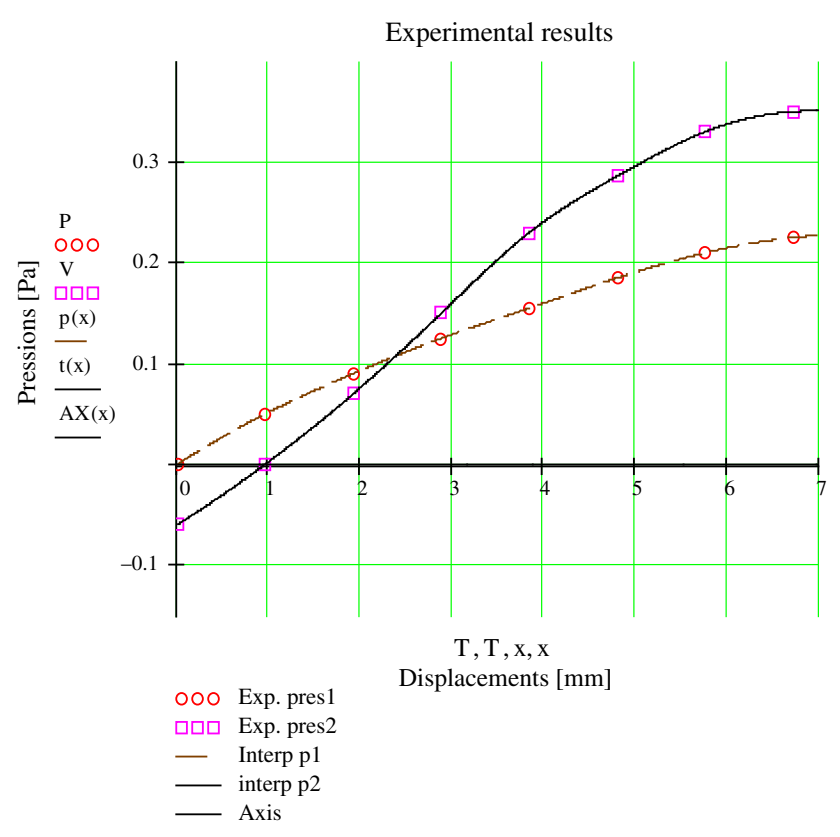

Fig. 8 Presentation of the experimental study for research pressure in a hydraulic cylinder that simulates well with topdrive plant design at DTS

because pressure variation is caused by movement of the PM.

The foundation is a hydraulic cylinder which simulates the action of the weight of the drilling pressure and friction forces or other forces (Marken 1992; Mnatsakanov and Litvinov 1991).

Mobile platform is a building entirely made of board.

Geometric and dimensional configuration and materials used strictly observed conditions to scaling of the actual dimensions.

Moving the mobile platform as well as raising or lowering the load is ensured by two or, alternatively, four linear hydraulic motors coupled to drive the main hydraulic circuit (Martin 2003).

We have a pressure transducer placed over the piston and the second below. In both places the estimated duration curves are observed. You cannot see the difference displacement of the drilling heads.

Hydraulic cylinder displacement shows that topdrive produces a pressure variation in probe similar in evolution.

Experimental data study in a hydraulic cylinder that simulates well drilling is shown in Fig. 8.

\section{The experimental research}

Tension and displacement can be determined with good precision using electronic computer using specialized software. These programs can perform a complete static analysis and dynamic analysis-oriented application.

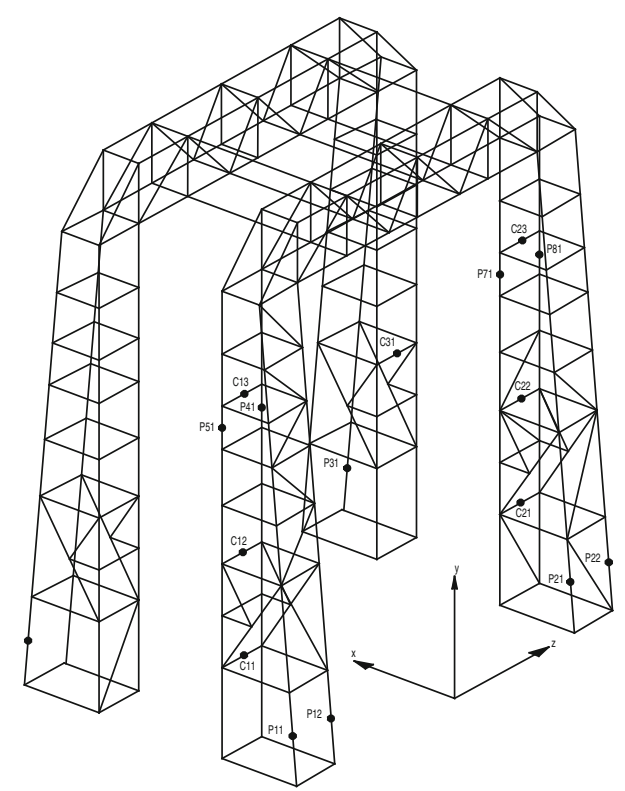

Fig. 9 Plan scheme of resistive transducers measurement (Subramanian and Azar 2000)

Structure of the guidance relies on a metal structure that simulates the real way of connecting with the foundation of the real structure.

The experiment was integrated into a computer simulation to model the stresses and movements (Fig. 9).

Determining the stress and deformation at numerical simulation leads to conclusions about where it develops in elements indicating the highest value of normal tension and displacements for beams. Simulation is performed to avoid detection capability of the structure to tilt top platform topdrive.

An important result it is angle of inclination $\alpha=4^{\circ} \div$ 4.5 and is over the state limit of resistance for steel pipe used. The model material requires acceptance of a reservation of assurance that the maximum angle of inclination to the PM to be $\alpha \operatorname{Max}=3^{\circ}$.

\section{Conclusions}

In the author's view, an important contribution is to clarify the interaction of a drill string and unconventional hoisting system, we find the influence of the constructive peculiarities oil installations (drilling, onshore or offshore.

Dynamic study of the drilling results in identifying how variation of the forces acting on the hoisting system.

In this sense, there were two issues:

- Develop mathematical model for the study of dynamic drill string.

- Study of the effects on the structure of mechanical wave propagation directions of the drill string. 
In the first case, the mathematical models against existing energy determined by the method proposed by various researchers have made some original and important contributions by including in the mathematical equations of the model, given the constraint:

1. of the effect of drilling fluid gel

2. to that of "piston "by the appearance of additional pressure at drilling bit. These effects are particularly pronounced in drilling large diameter or deep drilling.

It was also considered that the energy dissipation is due to viscous damping gasket, dry and as a novelty structural damping.

Simulation of the dynamic model shows that early surgery maneuvering, acceleration reduced mass movement has elevated mobile platform, coupled with a significant increase in extraction force of the drilling of the well.

This is caused by the inertia of the system, overcoming the resistance of the gel and hydrodynamic pressure due to the piston effect.

The results do not change in terms of quality depending on the length of the drilling or its diameter. Shorter lengths of drill string increase its stiffness and acceleration and force oscillation amplitudes are significantly reduced.

Measurement and drawing graphic variation stand pressures indirect health as a way to compare the results of the theory (Fig. 3) with experimental measurements (Fig. 8).

Along with the evolution parameters remember the drill string spreads mechanical waves, whose evolution was studied with a suitable mathematical model.

These mechanical waves can be dangerous for both the drill string (the threaded joints) and for guiding structure on the surface over which is reflected in their effect.

We see in Fig. 5, large values of accelerations at startup, which means high dynamic stresses. Shown in Figs. 3, 4, 5 , disturbances, major longitudinal vibrations. They depend on the choice of material, see Table 1.

Identifying these modes of variation of the variables of effort, i.e., speed, carried the article, makes it possible to switch to directly study the effects induced rolling elements guiding structure represented raceways.

The built stand equipped with strain trademarks highlights the evolution of the mechanical stress simulated with hydraulic cylinder the drill string. Research stresses the second major utilization of the stand. We can design hydraulic cylinders displacement for topdrive that is not synchronous movements. It is important to limit these imperfections.

All these situations are analyzed elements in oilfield equipment research and design and is a very useful initial volume of the final goal of guiding the execution structure.
There are many elements of design automation and computers automatically, which is the ultimate in computer-aided design system.

The main contributions:

- Determining the mechanical model of the drilling by adding the variants already developed resistance gel effects and additional hydrodynamic pressures occurring in shunting and model structural damping;

- Establish a mechanical model of the drilling for the study of mechanical wave propagation by considering the effects they produce;

- Computer-aided simulation of these models and results;

- Identify how the interaction between the system and the structure of unconventional hoisting system, structure for guidance is influenced by variation of speed and power;

- Build a stand for the experimental research of stress and strain directions structures;

- Confirmation of theoretical research by experimental results indicating that under the effect desync movement and speed mobile platform increasing the mechanical stress;

- Specifying a desync parameter limit values for the model developed, which should be considered.

To achieve the objectives, the work is considered a point basis for developing other papers and scientific articles. The author states that it can provide source software written for solving the model of the drilling for those interested.

Last but not least I want to make known this model is a research simulator to various problems related to drilling rigs for deep wells or drilling large diameter.

Open Access This article is distributed under the terms of the Creative Commons Attribution License which permits any use, distribution, and reproduction in any medium, provided the original author(s) and the source are credited.

\section{References}

Abrahamsen E, Reid D (2007) Improved well construction enabled by next generation top drive casing running and drilling tools, Weatherford Intl. Inc, SPE/IADC Drilling Conference, 20-22 February 2007, Amsterdam, The Netherlands

Abrahamsen E (2007) SPE, Improved well construction enabled by next generation top drive casing running and drilling tools. SPE/ IADC Drilling Conference

Avram L (1995) Guidance for Determining some Thermo- dynamic Variables during the Process of Well Cementing (with special references to wells with large diametre), The Petroleum-Gas University of Ploiesti

Avram L, Stan M (2010) Study concerning the use of terrestrial experience in the domain of trial boring during the well water drilling on the Mars surface, Buletinul Universitatii Petrol-Gaze din Ploiesti, No 1 
Avram L, Troquet M (1999) Effects of ezothermic cement duringcasing cementing of driller mine. Materials and Techniques, no 9-10, Paris

Fraser C, Hitec Products Drilling; White G, SPE, Rowan Drilling; DePeuter E (2009) LeTourneau Technologies SPE/IADC Drilling Conference and Exhibition, 17-19 March 2009, Amsterdam, The Netherlands

Kim H (2010) Dynamics of large diameter riser. The twentieth international offshore and polar engineering conference, 20-25 June, Beijing, China Publication

KT5000 type fully hydraulic power big diameter drilling rig. http:// zhengzhouhanfa.en.made-in-china.com

Mnatsakanov AV, Litvinov AI (1991) Hydrodynamics of the drilling in deep, thick, abnormal pressure reservoirs. SPE/IADC Drilling Conference, SPE-21919-MS

Martin H (2003) Automated drilling application for gaining higher efficiency on extended reach wells. SPE/IADC Middle East Drilling Technology Conference and Exhibition

Marken CD (Rogaland Research) | Xiaojun He (Rogaland Research) | Arild Saasen (Rogaland Research) (1992) The Influence of Drilling Conditions on Annular Pressure Losses, SPE Annual
Technical Conference and Exhibition, 4-7 October, Washington, D.C., SPE-24598-MS

Nguyen JP (1993) Le forage. Editions Technip, Paris

Piroozian A, Issham I, Zulkefli Y, Parham B, Ahmad S, Izwan I (2012) Impact of drilling fluid viscosity, velocity and hole inclination on cuttings transport in horizontal and highly deviated wells. J Petrol Explor Prod Technol 2:149-156

Subramanian R (Born Inc.) | J.J. Azar (University of Tulsa) (2000) Experimental study on friction pressure drop for nonnewtonian drilling fluids in pipe and annular flow, international oil and gas conference and exhibition in China, 7-10 November, Beijing, China, SPE-64647-MS

Shields RG (Canadian Marine Drilling Ltd.), Large-Diameter Glory Hole Drilling: The Evolution From 12- to 20-ft Diameter, 1994. Society of Petroleum Engineers

Spanos PD, Payne ML, Secora CK (1997) Bottom-hole assembly modeling and dynamic response determination. J Energy Resour Technol 119(3):153-158. doi:10.1115/1.2794983

Stan M (2010) Dynamic system composed of topdrive and drill pipe, Buletinul Universitati Petrol-Gaze din Ploieşti, vol LXII No. 1 